\title{
Topical and Regional Treatment for Osteoarthritis
}

\author{
Leena Patel ${ }^{1}$ and Charles Mackworth-Young ${ }^{2}$ \\ ${ }^{1}$ Department of Rheumatology, Whipps Cross University Hospital, London \\ 2Department of Rheumatology, Charing Cross Hospital, London,
}

UK

\section{Introduction}

Osteoarthritis (OA) is the most common joint-related disorder. The prevalence rises steeply with age and is a major cause of pain and disability. In the over 65 -year-old population, $12 \%$ suffer from symptomatic knee OA (1) while 13- $26 \%$ suffer from symptomatic OA in at least one hand joint (2). Hip OA is much less common. The prevalence of radiographic change is much higher; in the elderly population $75 \%$ have evidence of hand OA and $30 \%$ of knee OA on plain radiographs (3).

The term "osteoarthritis" is used to refer to a number of related conditions that can be broadly classified into two groups. Primary OA, which can be localised or generalised and more commonly affects peri-menopausal woman (especially involving the hand interphalangeal joints); or secondary $\mathrm{OA}$ which has an underlying cause such as an inflammatory arthritis (e.g. rheumatoid arthritis or crystal arthritis), mechanical damage (e.g. articular fractures), a congenital or developmental disorder or a metabolic or endocrine condition (4). An osteoarthritic joint may show varying degrees of inflammatory change, detectable clinically and histologically. It is uncertain to what degree these (and other) subdivisions of OA are useful in terms of therapy.

This chapter addresses therapies for all forms of OA of limb joints. Much of the evidence that will be considered here does not distinguish between the various types, although where possible, efficacy in knee, hip and hand OA is described separately due to the differing natural history and prognosis of OA at these sites.

Treatments for OA are limited. They consist of a combination of non- pharmacological and pharmacological approaches, which should be tailored to the individual according to their needs and stage of disease. They aim to relieve pain and stiffness and thereby improve function. It is recognised that pain arises from both intra-articular structures (bone or synovial tissue) and from peri-articular structures such as entheses, bursae or tendons. Sensitisation of peripheral nerves and central nervous system changes can also contribute to the persistence of pain over time.

All patients should be offered education, advice and access to information in combination with physical approaches (e.g. strengthening exercises and physiotherapy, including aerobic fitness training) and lifestyle changes (e.g. weight reduction and dietary manipulation) as appropriate. Additional therapies include systemic drugs (e.g. analgesics, anti-inflammatory agents, supplements, and, recently, disease modifying treatment such as hydroxychloroquine) and surgery. 
This chapter focuses on treatments that are administered to the joint itself, or in the region of the joint. Pain management techniques such as nerve block and transcutaneous electrical stimulation are beyond the scope of the article.

\section{Specific therapies}

\subsection{Splinting/support}

Orthoses (or braces) are external devices mainly prescribed to modulate mechanical stress on a symptomatic joint compartment. They are used in knee and hand OA but not in hip OA. For knee OA, they include rest orthoses, knee sleeves and unloading braces. For hand OA they include thumb and wrist splints. Insoles are used in hip and knee OA: they include cushioned or neutral insoles, which act as shock absorbers; and wedged insoles, which also modulate mechanical stress.

For lower limb OA, the main purpose of orthoses and insoles is to support an unstable joint and to help correct alignment (5). In doing so, they reduce pain, reduce load bearing and improve physical function. They can also improve proprioception (6) and possibly slow disease progression (7). They are particularly recommended in mild or moderate unicompartmental knee OA $(8,9,10)$ where varying degrees of frontal or sagittal instability and varus or valgus mal-alignment occur, and ideally should be used in combination with other therapeutic approaches. The different interventions are described individually below.

1. Rest orthoses are made from a stiff composite and are intended for joint immobilization. They are rarely used in practice however, and there are no clinical trial data to suggest effectiveness. Whether they would be helpful in transiently immobilising a swollen knee remains uninvestigated (11).

2. Knee sleeves are functional elastic non-adhesive orthoses that can be used alone or in association with various devices and are aimed at patellar alignment or frontal femorotibial stabilisation. Simple neoprene knee sleeves used in medial compartment OA have been shown to reduce pain on activity and stiffness but not physical disability in the short term (6 months) when compared with no sleeve (12). This does not appear related to a local thermic effect. They have also been shown to increase static and dynamic balance, which might help prevent falls (13). Heat retaining sleeves (worn for 12 hours per day for 4 weeks) do not offer additional therapeutic benefit over standard devices (14). Medial patellar strapping has also been shown to reduce pain significantly in patello-femoral OA associated with patellar mal-alignment (15).

3. Unloading knee braces are functional devices indicated in patients with mal-alignment secondary to medial or lateral unicompartmental OA. They are composed of external stems, hinges and straps and are designed to decrease the compressive load transmitted to the diseased compartment by applying an external valgus or varus force respectively. Analgesic effect is achieved by improved stability, increased joint opening and possibly by reduction in local muscle contractions during gait (7).

A single randomized controlled trial (RCT) of 110 patients showed that a valgus brace significantly improved pain, functional status and disease-specific quality of life at six months compared with no intervention in patients with medial compartment knee OA, and was more effective than a neoprene sleeve (12). However, a further RCT did not confirm its efficacy in pain reduction (16). A subset of patients in this trial found the varus brace effective for lateral compartment OA; this is the only trial result supporting efficacy of varus bracing. Unloading braces have been shown to improve isokinetic 
quadriceps strength and gait symmetry (11) and while they significantly improve joint proprioception, this does not appear to improve postural control (6).

The main drawbacks with unloading braces are a variable response rate (39 to $93 \%$ of patients notice improvement) (11), and discomfort due to heaviness, heat and mobility of the device. The latter can also lead to persistent joint instability. In a three-year follow up study of 22 patients, the most common complaint was skin irritation affecting $41 \%$ of patients (17). Long-term compliance is therefore a problem: $20 \%$ of patients discontinue their brace at 6 months and many discontinue treatment within 1 to 2 years (18). Long term efficacy is therefore unknown. The most serious reported side effect is venous thromboembolism.

4. Insoles. There are limited data for the effectiveness of insoles (either laterally wedged or neutral) in reducing the symptoms of OA. In one study there was significant decrease in non-steroidal anti-inflammatory drug (NSAID) consumption and significantly better compliance in the laterally wedged insole group at 6 and 24 months compared to the neutral wedge group but there was no significant difference in pain, stiffness and function (19). Another study has shown that elastic subtalar strapping significantly reduces pain and femoro-tibial angulation at 6 and 24 months compared with traditional laterally wedged insoles (20). Adverse effects include low back, popliteal and foot sole pain (21). However, given their low cost and relatively better compliance, attention to footwear with shock-absorbing properties is worth considering (22).

5. Thumb Splints. In patients with hand OA, pain and its anticipation is a major factor in loss of hand function. Pain reduction should therefore be the primary goal of treatment. It appears that $1^{\text {st }}$ carpo-metacarpal $(\mathrm{CMC})$ joint $\mathrm{OA}$ contributes more to pain and disability than inter-phalangeal joint OA (23). As heavy stresses are placed on the $1^{\text {st }}$ $\mathrm{CMC}$ joint during pinching and grasping, thumb splints are useful especially if the patient has difficulty in performing daily tasks.

Their efficacy was shown in a systematic review in 2010, which found high to moderate evidence for thumb CMC joint immobilization in improving pain and function and moderate evidence in improving grip strength (24). A multi-centre trial also showed strong evidence for efficacy at twelve months (but not at one month) in terms of improved pain and disability (25). There are several different designs of thumb CMC splints (from a short opponens splint which supports the $1^{\text {st }} \mathrm{CMC}$ and metacarpo-phalangeal $(\mathrm{MCP})$ joint, to a much larger long opponens splint which includes both the MCP and wrist joint) (26). As yet it is unclear which are considered most comfortable for patients and thus will be worn long term, and what degree of support is required at what stage of $\mathrm{OA}$ in order to improve pain and function effectively (22).

\subsection{Topical non-steroidal anti-inflammatory drugs}

Direct application of topical non-steroidal anti-inflammatory drugs (NSAIDs) in the region of a painful joint is a common and recommended treatment in mild to moderate OA $(8,9,10,22)$. This treatment is particularly useful in the management of a single painful osteoarthritic joint (especially the knee), or when a few hand joints are involved. It can provide a safe and effective alternative to systemic anti-inflammatory therapy.

Topical NSAIDs act primarily through inhibition of cyclo-oxygenases responsible for prostaglandin biosynthesis at the site of pain and inflammation, but might also work through peripheral and central desensitisation (27). Unlike other topical treatments, the act 
of local rubbing appears less important in achieving a therapeutic effect. Topical NSAIDs can be applied over the affected joint up to 2 to 4 times a day depending on the drug, but currently are not recommended for continuous use beyond one month.

There are several different preparations of topical NSAID available, which differ in the active drug (diclofenac, ibuprofen, ketoprofen, piroxicam and felbinac), formulation (gel, solution, cream, plaster and patch) and the presence of a penetration enhancer to improve drug delivery (45.5\% dimethylsulfoxide [DMSO] or menthol). The most commonly studied preparations are diclofenac sodium 1\% gel (DSG) and diclofenac sodium $1.5 \%$ in $45.5 \%$ DMSO solution (Pennsaid).

To be effective, a topical NSAID needs to penetrate the skin and enter the circulation or additionally be absorbed into the underlying tissue. The formulation with respect to its lipid and aqueous solubility (requirements for passing through the stratum corneum and epidermal layer respectively) determines the degree of dermal penetration (28). Formulations of gels and sprays are more effective than creams.

Studies show that penetration of the topical NSAID into the intra- and peri-articular structures via the local bloodstream gives rise to therapeutic concentrations within these tissues without significant systemic absorption $(28,29)$. This accounts for their superior safety profile over oral therapy with respect to systemic renal, cardiovascular and gastrointestinal toxicity.

Peak concentrations in the skin are achieved 2 hours after application, with a second peak 10 hours after application, which is attributed to the systemic circulation. The skin appears to act as a 'reservoir' from which the drug is distributed to deeper tissues (30). Only 3-7\% of the applied dose is systemically absorbed (29) and mean plasma concentrations are typically $5 \%$ or less of the level reached following oral administration $(31,32)$. Low systemic absorption is evidenced further by the lack of symptom relief in other joints distant to the site of application (33).

With respect to knee osteoarthritis, up until recently there was no research evidence to support the long-term use (greater than a month) of topical NSAIDs; a systematic review in 1998 (34) and two meta-analyses in $2004(35,36)$ confirmed that topical NSAIDs were superior to placebo for up to two weeks in the treatment of chronically painful conditions but not longer. Later trials have however shown more long term efficacy, benefit beyond 4 weeks was confirmed in a meta-analysis of trials assessing efficacy between 4 and 12 weeks (37), and two further recent large high quality RCTs have demonstrated a sustained response maintained up to 12 weeks with diclofenac ("DSG" (33) and "Pennsaid" (38)) when compared with placebo. A recent RCT has also found topical ibuprofen to be as effective as oral ibuprofen and other NSAIDs for 12 months (39).

Currently there is insufficient evidence to compare efficacy of topical to oral administration of the same NSAID. The meta-analysis of RCTs in 2004 found that overall topical NSAIDs were less effective than oral NSAIDs (36). Two recent studies comparing topical diclofenac (in DMSO) with oral diclofenac in patients with knee OA have however demonstrated equivalent efficacy $(40,41)$.

Placebo controlled trials and head to head studies with oral NSAIDs also show efficacy of topical NSAIDs in finger joint OA: hence they are preferred to systemic therapy, especially for mild to moderate OA and when few joints are involved (42).

The main side effect of topical anti-inflammatory treatment is local application site reactions such as dry skin, rash, pruritis and burning $(36,37)$. They are short-lived and minor 
however, and usually resolve when application is discontinued. Studies show that local adverse events are reported with equal frequency for topical NSAIDs and placebo preparations; hence they appear not to be related to the NSAID itself (35). Safety between different topical agents has not been studied. However, three 12-week trials showed a greater incidence ( 5 to 8 fold higher) of local application site reactions with diclofenac in DMSO solution (26-42\%) compared with DSG (5.1\%) (33).

Compared to oral NSAIDs, topical therapy is associated with fewer systemic adverse events and gastro-intestinal side effects $(33,35,40,41)$. However, data regarding gastro-intestinal safety and tolerability of topical NSAIDs in older patients (over the age of 50 years) are conflicting. Some studies report minor side effects to be infrequent, including the two-year RCT comparing topical to oral ibuprofen $(39,43)$; but a recent systemic review has demonstrated gastro-intestinal adverse events in $15 \%$ and local skin reactions in $39.3 \%$ of patients receiving topical NSAIDs including skin sensitivity, contact dermatitis and photodermatitis (44).

While topical NSAIDs should be considered with paracetamol as first line treatment ahead of oral NSAIDs, COX-2 inhibitors or opioids in view of their efficacy and relative safety, further studies are needed to confirm their long-term efficacy and use in bilateral knee OA. Their use in older patients also might still require a degree of caution until further data demonstrating their safety profile in this age group become available.

\subsection{Topical counter-irritants}

Topical counter-irritants or rubefacients are agents that are frequently applied locally to relieve musculoskeletal pain in the extremities. The most commonly used rubefacient is salicylate, but this class of agent also includes nicotinate esters. Topical capsaicin is commonly considered to be a rubefacient; however its mechanism of action is sufficiently different for this treatment to be described separately.

The principal action of rubefacients is to act as a skin irritant. This results in reddening from vasodilatation and increased blood flow, but also leads to a soothing sensation of warmth i.e. counter-irritation. It is still unclear whether topical salicylates additionally relieve pain via cyclo-oxygenase inhibition, but there is little evidence that there is significant systemic absorption (45). This is consistent with the fact that no benefit is found using a rubefacient applied distal to the site of pain (46). Pain may also be offset or altered in the underlying muscle, joint and tendon by irritation of the sensory nerve endings (47). More recently there is evidence to suggest that salicylates and other rubefacients may act via the transient receptor potential (TRP) ion channels involved in thermal and pain sensation $(48,49)$.

Although topical rubefacients containing salicyclate are widely used in England (almost 1.8 million prescriptions issued in 2006) (50), there is currently no evidence to support their prescription for chronic musculoskeletal pain. A Cochrane analysis in 2009 of six studies of rubefacients in chronic conditions such as osteoarthritis has shown that they produced significant benefit compared with placebo at 14 days, with 1 in 6 individuals achieving $50 \%$ pain relief (51). This compares poorly with topical NSAIDs however, where the number needed to treat (NNT) is 3.1 compared to placebo. Additionally their efficacy may be over-estimated as adequate blinding is not possible with any trial involving a rubefacient, the mechanism of action is through local irritation and any sham preparation, which attempts to mimic this, would be a rubefacient itself. However, placebo gels in trials were rubbed on to the skin in the same way as the active treatment overcoming any additional therapeutic effect of rubbing (52). 
Based on limited data, rubefacients appear well tolerated and local adverse effects are uncommon in the short term $(2 \%$ of patients) $(51,52)$. Currently they are usually used as adjuvants to other therapies, such as oral analgesics, support bandages, rest, ice, and compression, and may be useful for patients who cannot tolerate oral analgesics (52). RCTs are needed to support their clinical use with respect to long-term efficacy and safety especially in osteoarthritis, which is a chronically painful condition. Most trials have lasted 14 days only and the longest trial spanned 28 days (52). Consequently rubefacients are not recommended in the UK in osteoarthritis although this recommendation has been based on a small number of limited studies (22).

\subsection{Topical capsaicin}

Topical capsaicin $(0.025 \%)$ cream can be used to treat pain from osteoarthritis and rheumatoid arthritis. A higher dose $(0.075 \%)$ is used in the treatment of neuropathic pain. The preparations contain capsaicin, a lipophilic alkaloid extracted from chilli peppers that has an extremely potent irritant effect. They work by initially selectively activating and sensitising c-nociceptors in the skin by binding the transient receptor vanilloid type 1 (TRPV 1) cation channel (53). Substance $P$ is released which causes local irritation; however with repeated applications, levels are depleted leading to reversible desensitization of pain fibres and eventual degeneration of epidermal nerve fibres resulting in hypoalgesia (54). Although topical capsaicin is better than placebo for treatment of chronic pain, a meta-analysis of topical capsaicin $(0.025 \%)$ or plaster for chronic musculoskeletal pain calculated the NNT at 4 weeks to be 8.1 for a $50 \%$ reduction in pain suggesting that capsaicin is only marginally effective (55).

In general therefore topical capsaicin is best employed as an adjunct to other modes of therapy. It should be used for 3 to 4 weeks (applied 4 times daily) to achieve maximal benefit. A transient local burning sensation (which can be intense), stinging or erythema at the application site are common (40\%) (10), and lead to 1 in 10 patients discontinuing the treatment (55) however. Systemic events are rare.

\subsection{Thermotherapy}

The local application of heat or cold (cryotherapy) to a painful joint has been used for many years in the rehabilitation of patients with OA to relieve pain, stiffness and oedema. Cryotherapy is usually administered by application of cold packs or massage with ice over painful areas or acupoints (56). Cold application helps to reduce pain and swelling by causing temporary vasoconstriction and a reduction in local blood flow. This may in turn help improve range of motion and function (57). Heat therapy is used to reduce pain and stiffness by possibly improving circulation and relaxing muscles. However there are concerns that increased blood flow may worsen inflammation and oedema. Common methods of superficial heat administration are electrical heating pads, application of hot packs, towels or wax, or immersion in warm water or wax baths.

Supporting evidence for the efficacy of this mode of treatment remains very limited. For knee osteoarthritis, ice massage may be a useful adjunct for pain relief and cold packs may be used to lessen knee oedema (Cochrane review of three RCTs in 2003, involving 179 patients) (58). Ice massage for 20 minutes, 5 times a week for 3 weeks had a clinically significant effect on knee strength $(29 \%$ improvement) with a statistically significant improvement in range of movement ( $8 \%$ relative difference) and function (11\% relative 
difference) after two weeks of treatment (59) but not at three weeks given three times a week (60). Ice packs did not affect pain significantly compared to controls; however ice massage did have a significant effect. Cold packs also lead to a significant reduction in knee swelling but this has not been seen with hot packs (61). Some studies have shown that heat therapy for knee OA used for 20 minutes every other day for four weeks can significantly improve pain and disability but not stiffness (62). There have been no controlled trials of cryotherapy in hip OA.

There are no experimental studies to examine the role of cryotherapy in hand osteoarthritis. However, a systematic review in 2010 found three studies that had examined the role of heat therapy in 174 patients (63). There is weak evidence for the role of paraffin wax in pain reduction, improved range of movement and function, and moderate level evidence to support the use of low level continuous heat wrap and steam treatments for pain reduction and improved grip strength (64). Local application of heat prior to exercise may be helpful in knee OA; however direct research evidence for the benefit of local application of heat as a pretreatment or in combination with other physical therapies for hand OA is lacking (42).

Although further studies are required to determine their efficacy, heat and cold therapies are easy, non-invasive treatments with very few adverse events, and therefore can be considered as an adjunct to core treatment in hand and knee OA.

\subsection{Joint aspiration}

Aspiration of synovial fluid from a swollen joint (e.g. aspiration of knee) can provide temporary relief in pain and stiffness, although effusions usually re-accumulate unless steroid is injected. Aspiration of cystic fluid in cystic OA of joints similarly often provides symptomatic relief, but again fluid tends to re-accumulate.

\subsection{Intra-articular corticosteroid}

Intra-articular (IA) corticosteroid injections have been widely used to treat symptomatic peripheral joint $\mathrm{OA}$ for many years. The corticosteroid exerts its anti-inflammatory effect by interrupting the immune and inflammatory cascade at several levels. Local delivery of high doses of corticosteroid minimises systemic toxicity and can result in rapid improvement in symptoms during acute or severe symptom flares, especially in knee and hand OA.

Corticosteroid preparations differ in solubility and potency: more soluble preparations have a shorter duration of action, e.g. hydrocortisone acetate, compared to longer acting emulsion based preparations, which are only slightly soluble, e.g. methlyprednisolone acetate (MPA) or relatively insoluble, e.g.triamcinolone acetonide (TCA). Longer acting preparations are more effective for intra-articular injections as they remain in the joint longer, but there are few randomised, controlled trials comparing different IA corticosteroids. In a double blind RCT of 57 patients with symptomatic knee OA comparing TCA $20 \mathrm{mg}$ with MPA $40 \mathrm{mg}$, there was a greater reduction in pain compared with baseline at 3 weeks with TCA compared to MPA, but this was only maintained at 8 weeks in the MPA group despite TCA being less soluble (65). In practice the choice of agent is usually based on local availability and cost. The dose-response relationship has not been systematically studied.

Most manufacturers advise against corticosteroid dilution with local anaesthetic (e.g. lignocaine) because of the risk of clumping and precipitation of steroid crystals. However this remains common practice and provides additional benefits: there is early 
temporary relief of symptoms; it verifies delivery of steroid to site of pain (66); and it dilutes the suspension, enabling even distribution within the joint, (especially in shoulder joint injections), and hence avoids placement of highly concentrated fluid into a single area.

Several randomised controlled trials (67-70) and one Cochrane systematic review (71) have shown significant short-term efficacy (between 1 to 4 weeks) in terms of pain reduction for a single IA corticosteroid (TCA, MPA and cortivazol) over placebo in knee OA although effects on function appear less marked. There was no significant benefit at 4 to 24 weeks post injection. Hence IA corticosteroids work rapidly, but the effects are mostly short-lived. The lack of a sustained response over placebo in these studies might relate to lower than recommended steroid doses used, and a strong beneficial effect seen in patients receiving IA placebo injection. In clinical practice, IA steroid injections provide rapid short-term pain relief to settle flares of pain and permit patients to begin other interventions such as quadriceps strengthening exercises.

The benefit of IA corticosteroid injections to the hip remains inconclusive. One small RCT of 35 patients examining the role of TCA in patients awaiting hip replacement showed good pain relief at one month, but this was not maintained, and in $8.5 \%$ symptoms deteriorated (72). Another RCT showed significant improvement by IA MPA 40mg at 2 weeks compared with placebo $0.9 \%$ saline injection, but efficacy was lost at 3 months (73).

The efficacy of IA $1^{\text {st }} \mathrm{CMC}$ joint injection was evaluated in a trial of 40 patients with primary moderate to severe OA, randomized to either $0.25 \mathrm{mls}$ TCA $(5 \mathrm{mg})$ or an equivalent volume of $0.9 \%$ saline. No clinical benefit was gained compared to placebo injection (74). A further prospective study of 30 patients with radiographically staged hand OA has shown long-term benefit (18 months) with a single IA 1st CMC joint injection and subsequent splinting for 3 weeks, in $80 \%$ of patients with early radiographic disease i.e preserved joint space and minimal other changes. In patients with more radiographically advanced $\mathrm{OA}$ with osteophytes and joint space narrowing, sustained pain relief was less reliably achieved (75).

While IA corticosteroids have marked anti-inflammatory effects and reduce the volume of synovitis in OA (73), disease factors which might relate to the presence of inflammation have not been found to determine clinical response including local heat and synovial thickening (70), and synovial fluid (SF) volume and leucocyte count (69). Furthermore the presence of a knee effusion does not appear to predict response either $(67,70)$. In one study prior synovial fluid aspiration did lead to a greater reduction in pain (69); however this may have been related to less steroid dilution by synovial fluid and more accurate placement of the IA injection confirmed by prior synovial fluid aspiration (76). Hence the presence of a knee effusion is not necessarily an indication for corticosteroid injection unless it causes significant restriction in movement. (22)

Additionally a steroid response is not confined to joints with clinical evidence of inflammation (70). This appears not to be related to inaccuracy in detecting inflammation on clinical examination; a recent ultrasound scanning study showed that patients with noninflammatory features on ultrasound derived more prolonged benefit compared to patients with inflammatory features (77).

The risks in IA steroid injection are generally small but the following potential side effects can occur: 
1. Post-injection crystal-induced synovitis can occur in 2 to $6 \%$ of patients. It is usually observed within 24 hours of injection, and spontaneously resolves in 1 to 3 days (78). It is usually managed by analgesic therapy or ice packs. Flares have also been reported following saline injection suggesting that other factors such as injection technique may be responsible $(67,69)$.

2. Iatrogenic infection is rare, with a reported incidence between 1 in 3000 to 1 in 50000 (79). Symptoms usually occur within 3 to 4 days of injection. Aseptic technique and withholding injection in at risk patients should minimise this potential serious complication.

3. Lipoatrophy secondary to subcutaneous deposition of steroid is more common with less soluble preparations and was found to occur in $0.6 \%$ of patients in a prospective study of intra- and peri-articular injections of methylprednisolone acetate (80). Hence longer acting preparations are generally avoided in small joint injections where accurate placement is technically difficult.

4. Local effects including tendon weakening/ rupture, muscle wasting, skin pigmentation changes, nerve and blood vessel damage can be minimised by more accurately directed injections.

5. Systemic effects vary. Facial flushing is relatively frequent (40\% in one study) (81) and may occur after a few hours. Diabetic control may be temporarily disturbed but not significantly (82). Corticosteroid-induced osteoporosis does not appear to be a major concern due to lack of net impact on bone resorption. Anaphylaxis is extremely rare (81).

Concern regarding long-term effects of repeated injection, such as risk of progressive articular cartilage damage, has limited the number of injections given to any particular joint: the general consensus is for no more than 3 to 4 per year. While animal studies have shown steroid induced chondrocyte degeneration (83), data to support this recommendation in clinical practice are lacking. In a randomised prospective trial of patients receiving TCA injections every 3 months for up to 2 years for knee osteoarthritis, no evidence of increased loss of joint space was observed (84). Similarly there are very few reports of osteonecrosis, with no convincing causal relationship identified. Unpublished experience does however suggest that there may be an increased risk of osteonecrosis of the femoral head following such injections into the hip joint.

Repeated intra-articular corticosteroid injections do not provide long-term benefit (76), and it is generally accepted that other treatment modalities should be sought if patients require frequent or numerous injections.

\subsection{Intra-articular hyaluronic acid/ hyaluronan}

Endogenous hyaluronan, previously known as hyaluronic acid (HA), is a large linear glycosamino-glycan. It is a major non-structural component of both the synovial and cartilage extracellular matrix and of synovial fluid. Key functions in the joint are to confer viscoelasticity and lubrication, and to help maintain tissue hydration and protein homeostasis by preventing large fluid movements (22). OA is associated with a decrease of HA content in the synovial fluid (85). The therapeutic goal of intra-articular viscosupplementation with HA is therefore to restore the natural protective function of hyaluronan in the joint.

The mechanism by which HA exerts its therapeutic effect, if any, is not certain. Intraarticular residency is short (hours), but the reported benefit is long (months). The short-term 
mode of action might be based on the pain relieving effect of the viscoelastic fluid in the affected joint. In the long term a sequence of events might be triggered which restores the trans-synovial flow and subsequently the metabolic and rheological homeostasis of the joint (86). However there is minimal evidence for a role in long term disease modification (8). Commercial preparations of HA have the same structure as endogenous HA, although cross-linked HA molecules (known as hylans) were later engineered in order to obtain greater elasto-viscosity and intra-articular dwell-time. There are several formulations available (Artz, BioHy, Durolane, Hyalgan, Synvisc, Suvenyl, Orthovisc, Replasyn and Suplasyn) which vary in their molecular weight ( 2 to over 7 million KDA). This difference is thought to be of importance with respect to the volume and number of injections needed, and the length of time the preparation remains in the joint. Higher molecular weight preparations, such as Hylan G-F 20 (Synvisc), seem to be more effective than lowermolecular-weight preparations in this respect (87).

Although there are a large number of studies in the literature, evidence for the efficacy of HAs is difficult to interpret because studies have used different molecular weights of HA and different injection schedules, and because of poor trial design. In addition, the benefit from placebo saline injections was high in some of the studies. Overall, hyaluronans and hylan derivatives seem to be superior to placebo in terms of efficacy (including pain relief, function and patient global assessment) and quality of life outcomes in patients with knee $\mathrm{OA}$ at different post-injection periods, but especially at 5 to 13 weeks after the last of a series of 3 to 5 injections (86). Clinical trials do not suggest that sub-groups of osteoarthritis patients may have greater benefit; however this would be of research interest given the high cost of this particular treatment (22). Data from the Cochrane meta-analysis suggest that IA therapy with hyaluronans may have a more prolonged effect than IA corticosteroids (86). Adverse effects are rare but include a transient increase in pain and very rarely a frank arthritis flare with knee effusion. There do not appear to be any systemic side effects.

In hip OA, no significant differences between hyaluronans and placebo were reported at any time point by a RCT evaluating efficacy and function outcomes, but the effect was better in patients without an effusion (88). There was no significant difference between hyaluronan and corticosteroid injection either (88). Similarly, hyaluronan and corticosteroid injections perform similarly with respect to efficacy and function in hand OA (89).

Overall the evidence for HA efficacy is mostly in knee OA, with a slower onset of action but a more durable response than IA corticosteroid injection. It is a safe treatment. However its widespread use is limited by cost. It is usually offered to patients who are not fit for or would like to delay surgical intervention, and in patients who require repeated IA corticosteroid injections.

\subsection{Acupuncture}

Accupuncture is a recommended modality of therapy for symptomatic treatment of patients with knee and hip OA. It involves treatment with fine filiform stainless steel needles of 0.25 $0.35 \mathrm{~mm}$ diameter. Typically six needles are placed near the painful area and possibly elsewhere and are either manipulated to produce a 'needle sensation' or stimulated electrically (electroacupuncture) for up to 20 minutes. A course of treatment usually consists of six or more sessions. The response can be variable, the reasons for which are not well understood. Potential underlying neurophysiological mechanisms are complex. The 'gate control theory' and release of endogenous opioids are possible explanations for the apparent analgesic effect (10). 
Although an earlier systematic review of acupuncture in patients with $\mathrm{OA}$ at various peripheral sites did not show it to be any better than sham controls (90), several randomized trials report benefit in knee OA over sham acupuncture (91-93) and standard treatment (94). A systematic review in 2001 of 7 RCTs including 393 patients (95) found that acupuncture significantly improved pain compared with sham acupuncture, but not function $(92,93)$. However, it was not found to be more effective than physical therapy or than being on a waiting list to receive acupuncture $(94,96)$. The benefit appears short to medium term (6-12 weeks); the few studies with long-term follow up did not show benefit at 26 weeks $(91,94)$. Combining acupuncture with a course of advice and exercise has not been shown to provide any additional benefit (97). Acupuncture of peripheral joints appears safe (98). Mild adverse effects occur in $7 \%$ of patients $(99,100)$, but serious side effects are rare $(101)$.

\subsection{Trigger point injection}

In many forms of arthritis, localised areas of thickening and tenderness in cutaneous and other soft tissues can be found. These have been referred to by a number of different names, including interstitial fibrositis, myofasciitis and myofascial trigger points (102-104). They are also well described by acupuncturists (105). Some are found clinically in cutaneous and subcutaneous tissue at sites near to or distant from inflamed or painful joints, typically in areas of a limb proximal to an affected joint, such as in the upper part of the rectus femoris in patients with knee pain, and in paraspinal regions in the cervical and lumbar areas (106). The term trigger point injection (TPI) refers to direct injection of a substance into the trigger point itself, or into the skin or soft tissue over the trigger point (indirect needling); or to dry needling of either of these areas. The main objective is to inactivate the trigger point thereby reducing pain and restoring function. However, the aetiology and pathogenesis of trigger points have yet to be elucidated, and the precise mechanism by which TPI inactivates the trigger point is still unknown (107).

Optimal technique and treatment regimen for TPI varies between practitioners, and is largely based on clinical experience. Treatment begins with identifying the trigger point; the area of maximal tenderness and immobilising the muscle between the thumb and forefinger. Generally a sterile small gauge needle is then introduced into the trigger point. Correct identification is supported by a twitch in the affected muscle, exacerbation of pain and the presence of referred pain (108).

Clinicians have used local anaesthetic, anti-inflammatory agents (long-acting corticosteroid, acetylsalicylate and ketorolac), saline and water (104,108-113). Injecting a trigger point is painful and the addition of a local anaesthetic to the injected fluid can help reduce pain and irritation $(114,115)$.

A systematic review of the efficacy of TPI to treat chronic non-malignant musculoskeletal pain (such as whiplash syndrome or chronic head, neck, shoulder, and back pain) of more than three months' duration found that TPI relieved symptoms when used as a sole treatment for patients, regardless of the injectant used, but was not more effective than other less invasive treatments such as laser and ultrasound (107).

The efficacy of TPI as a treatment for osteoarthritis is not well described; and as most studies have looked at its role as a sole treatment rather than in the adjunct capacity in which it is routinely used in clinical practice, its effectiveness might be underestimated. One study showed that intra-articular injection combined with lidocaine TPI of any of the 15 leg muscle trigger points was more effective than intra-articular injection alone in relieving pain and 
improving knee function in a highly selected group of older patients with knee osteoarthritis (116). Except for the rare occurrence of muscle atrophy at the injection site, very few adverse events are reported with TPI and it is currently recommended as an adjunct therapy in osteoarthritis.

\subsection{Subcutaneous sodium salicylate injection}

Trigger point injection using sodium salicyclate has also been studied. In a large uncontrolled study Fox reported a good response from injecting $0.5 \%$ sodium salicylate into superficial areas of tender soft tissue thickening: using multiple injections, he recorded an improvement in symptoms in $79 \%$ of patients at 12 weeks (117). Most of these subjects had osteoarthritis.

Following similar preliminary observations in our group, we performed a pilot study, in which 16 patients with OA of the first (thumb) CMC joint were treated with injections of $0.5 \%$ sodium salicylate or saline into similar areas of superficial soft tissue thickening (118). There was a significant improvement in pain score in both groups. The improvement was better maintained in the patients that received salicylate. A subsequent double-blind study of 40 patients with the same condition showed superiority of sodium salicylate injections over sham injections (119). Pain and tenderness during follow up were both significantly lower in the active treatment group compared with the sham group.

The chief limitation in studies of this kind is the imperfect nature of the control treatment. However, in the sham-controlled study, the improvement in the active treatment group was sustained for as long as 13 weeks, suggesting that an effect greater than placebo was being observed. Furthermore, there was no significant correlation in the active group between the pain of the injections and response in terms of pain in the joint.

The mechanism of action of this treatment is uncertain. The injected patches are distant from the affected joint. It is possible that the salicylate causes a change in the control of pain, perhaps through a modification of central sensitisation. This would be consistent with reports by patients of improvement in symptoms within minutes. The treatment could modify the neurogenic control of inflammation, which may be disturbed in musculoskeletal disease $(120,121)$. One way in which this might occur could be through changes in the expression or transport of neurogenic peptides (122), brought about by an irritant effect of the salicylate, similar to that of topical capsaicin $(55,123)$. A systemic anti-inflammatory effect is unlikely, since similar injections of salicylate at other sites fail to produce any effect on the symptoms of osteoarthritis (Mackworth-Young C.G., personal observation).

It could be that sodium salicylate injection therapy acts in a manner similar to acupuncture, but achieves a more prolonged effect because a substance is injected into the tissues that results in a sustained stimulus. Many of the injected patches occur at standard acupuncture sites.

Sodium salicylate therapy is inexpensive, and can be administered by general practitioners and trained nurses. The studies on this treatment also suggest areas for further scientific enquiry in the regulation of pain and inflammation in osteoarthritis.

\section{Conclusions}

There are many local therapies available for the treatment of patients with limb joint OA. Some are well established, such as intra-articular corticosteroid. Some are relatively new, and show promise for further development. 
Most of them are primarily symptomatic treatments, which need to be tailored to the individual's preference and tolerance. Many of them function well as adjuncts to other treatments, such as systemic analgesics or anti-inflammatory agents. Given the chronicity of OA however, they are likely to be required over long periods of time, either continuously or as episodic treatment during symptom flares. Long-term efficacy data are largely missing, although the therapies appear to be generally safe. Furthermore studies for costly interventions with proven efficacy such as hyaluronan injections are needed to identify subsets of patients who would benefit most from the treatment to allow more targeted use. It is uncertain if some treatments may modify medium or long-term outcome. For example in inflammatory OA of small finger joints, it is not clear whether intra-articular steroid injection hastens the settling down of the inflammation (which tends to happen anyway), and thus reduces the amount of joint damage. Similarly, effects of topical NSAIDs, acupuncture and subcutaneous sodium salicyclate injections on disease modulation are unknown. Longitudinal studies on these treatments may answer these questions.

\section{References}

[1] Felson DT, Zhang Y. An update on the epidemiology of knee and hip osteoarthritis with a view to prevention. Arthritis Rheum 1998; 41(8): 1343-55.

[2] Zhang Y, Niu J, Kelly-Hayes M, Chaisson CE, Aliabadi P, Felson DT. Prevalence of symptomatic hand osteoarthritis and its impact on functional status among the elderly: The Framingham Study. Am J Epidemiol. 2002; 156(11): 1021-7.

[3] Arden N, Nevitt M. Oeseoarthritis: Epidemiology. Best Pract Res Clin Rheumatol. 2006; 20(1): 3-25.

[4] Haq I, Murphy E, Dacre J. Osteoarthritis. Postgrad Med J. 2003; 79(933): 377-83.

[5] Rannou F, Poiraudeau S, Beaudreuil J. Role of bracing in the management of knee osteoarthritis. Curr Opin Rheumatol. 2010; 22(2): 218-22.

[6] Birmingham TB, Kramer JF, Kirkley A, Inglis JT, Spaulding SJ, Vandervoort AA. Knee bracing for medial compartment osteoarthritis: effects on proprioception and postural control. Rheumatology (Oxford). 2001; 40(3): 285-9.

[7] Ramsey DK, Briem K, Axe MJ, Snyder-Mackler L. A mechanical theory for the effectiveness of bracing for medial compartment osteoarthritis of the knee. J Bone Joint Surg Am. 2007; 89(11): 2398-407.

[8] Jordan KM, Arden NK, Doherty M, et al. EULAR Recommendations 2003: an evidencebased approach to the management of knee osteoarthritis: Report of a Task Force of the Standing Committee for International Clinical Studies Including Therapeutic Trials (ESCISIT). Ann Rheum Dis. 2003; 62(12): 1145-1155.

[9] Recommendations for the medical management of osteoarthritis of the hip and knee: 2000 update. American College of Rheumatology Subcommittee on Osteoarthritis Guidelines. Arthritis Rheum. 2000; 43(9): 1905-15.

[10] Zhang W, Moskowitz RW, Nuki G, et al. OARSI recommendations for the management of hip and knee osteoarthritis, Part II: OARSI evidence-based, expert consensus guidelines. Osteoarthritis Cartilage. 2008; 16(2): 137-162.

[11] Beaudreuil J, Bendaya S, Faucher M, Coudeyre E, Ribinik P, Revel M, Rannou F. Clinical practice guidelines for rest orthosis, knee sleeves, and unloading knee braces in knee osteoarthritis. Joint Bone Spine. 2009; 76(6): 629-36. 
[12] Kirkley A, Webster-Bogaert S, Litchfield R, Amendola A, MacDonald S, McCalden R, Fowler P. The effect of bracing on varus gonarthrosis. J Bone Joint Surg. 1999; 81(4): 539-48.

[13] Chuang SH, Huang MH, Chen TW, Weng MC, Liu CW, Chen CH. Effect of knee sleeve on static and dynamic balance in patients with knee osteoarthritis. Kaohsiung J Med Sci. 2007; 23(8): 405-11.

[14] Mazzuca SA, Page MC, Meldrum RD, Brandt KD, Petty-Saphon S. Pilot study of the effects of a heat- retaining knee sleeve on joint pain, stiffness, and function in patients with knee osteoarthritis. Arthritis Rheum. 2004; 51(5): 716-21.

[15] Warden SJ, Hinman RS, Watson MA Jr, Avin KG, Bialocerkowski AE, Crossley KM. Patellar taping and bracing for the treatment of chronic knee pain: a systematic review and meta-analysis. Arthritis Rheum. 2008; 59(1): 73-83.

[16] Brouwer RW, van Raaij TM, Verhaar JA,Coene LN, Bierma-Zeinstra SM. Brace treatment for osteoarthritis of the knee: a prospective randomized multicentre trial. Osteoarthritis Cartilage. 2006; 14(8): 777-83.

[17] Pollo FE, Otis JC, Backus SI, Warren RF, Wickiewicz TL. Reduction of medial compartment loads with valgus bracing of the osteoarthritic knee. Am J Sports Med. 2002; 30 (3): 414-21.

[18] Giori NJ. Load-shifting brace treatment for osteoarthritis of the knee: a minimum 21/2year follow-up study. J Rehabil Res Dev. 2004; 41(2) : 187-94.

[19] Maillefert JF, Hudry C, Baron G, Kieffert P, Bourgeois P, Lechevalier D, et al. Laterally elevated wedged insoles in the treatment of medial compartment osteoarthritis: a prospective randomized controlled trial. Osteoarthritis Cartilage. 2001; 9(8): 738-45.

[20] Toda Y, Tsukimura N. A 2-year follow up of a study to compare the efficiency of lateral wedged insoles with subtalar strapping and in- shoe lateral wedged insoles in patients with varus deformity osteoarthritis of the knee. Osteoarthritis and Cartilage. 2006; 14(3): 231-7.

[21] Brouwer RW, Jakma TS, Verhagen AP, Verhaar JA, Bierma- Zeinstra SM. Braces and orthoses for treating osteoarthritis of the knee. Cochrane Database Syst Rev. 2005; Jan 25; (1): CD004020.

[22] National Institute for Health and Clinical Excellence. Osteoarthritis: national clinical guideline for care and management in adults London: NICE, 2008. www.nice.org.uk/CG059.

[23] Bijsterbosch J, Visser W, Kroon HM, Stamm T, Meulenbelt I, Huizinga TW, Kloppenburg M. Thumb base involvement in symptomatic hand osteoarthritis is associated with more pain and functional disability. Ann Rheum Dis. 2010; 69(3): $585-7$.

[24] Kristin Valdes and Tambra Marik. A Systematic Review of Conservative Interventions for Osteoarthritis of the Hand. J Hand Ther. 2010; 23(4): 334-50.

[25] Rannou F, Dimet J, Boutron I, et al. Splint for base-of-thumb osteoarthritis: a randomized trial. Ann Intern Med. 2009; 150(10): 661-9.

[26] Batra S, Kanvinde R. Osteoarthritis of the thumb trapeziometacarpal joint. Current Orthopaedics. 2007; 21, 135-44.

[27] Doherty M, Jones A. Topical NSAIDs. In: Brandt K, Doherty M, Lohmander S, Osteoarthritis. 2nd ed. Oxford: Oxford University Press, 2003:291-5. 
[28] Haroutiunian S, Drennan DA, Lipman AG. Topical NSAID therapy for musculoskeletal pain. Pain Med. 2010 Apr; 11(4): 535-49.

[29] Anon. Topical analgesics: A review of reviews and a bit of perspective. www.jr2.ox.ac.uk/Bandolier/Extraforbando/ Topextra3.pdf 2005.

[30] Sioufi A, Pommier F, Boschet F, Godbillon J, Lavoignat D, Salliere D. Percutaneous absorption of diclofenac in healthy volunteers after single and repeated topical application of diclofenac Emulgel. Biopharm Drug Dispos. 1994; 15(6): 441- 9.

[31] Massey T, Derry S, Moore RA, McQuay HJ. Topical NSAIDs for acute pain in adults. Cochrane Database Syst Rev. 2010 Jun 16;(6): CD007402

[32] Brunner M, Dehghanyar P, Seigfried B, Martin W, Menke G, Müller M. Favourable dermal penetration of diclofenac after administration to the skin using a novel spray gel formulation. Br J Clin Pharmacol. 2005; 60(5): 573-7.

[33] Barthel HR, Haselwood D, Longley S 3rd, Gold MS, Altman RD. Randomized controlled trial of diclofenac sodium gel in knee osteoarthritis. Semin Arthritis Rheum. 2009; 39(3): 203-12.

[34] Moore RA, Tramer MR, Carroll D, Wiffen PJ, McQuay HJ. Quantitative systematic review of topical applied non-steroidal anti-inflammatory drugs. BMJ. 1998; 316(7168): 333-8.

[35] Mason L, Moore RA, Edwards JE, Derry S, McQuay HJ. Topical NSAIDs for chronic musculoskeletal pain: systematic review and metaanalysis. BMC Musculoskeletal Disord. 2004; Aug 19;5: 28.

[36] Lin J, Zhang W, Jones A, Doherty M. Efficacy of topical non-steroidal anti-inflammatory drugs in the treatment of osteoarthritis: meta-analysis of randomised controlled trials. BMJ. 2004; 329(7461): 324.

[37] Biswal S, Medhi B, Pandhi P. Longterm efficacy of topical nonsteroidal antiinflammatory drugs in knee osteoarthritis: Metaanalysis of randomized placebo controlled clinical trials. J Rheumatol. 2006; 33(9): 1841-4.

[38] Roth SH, Shainhouse JZ. Efficacy and safety of a topical diclofenac solution (Pennsaid) in the treatment of primary osteoarthritis of the knee: a randomized, double-blind, vehicle-controlled clinical trial. Arch Intern Med. 2004; 164(18): 2017-23.

[39] Underwood M, Ashby D, Cross P, Hennessy E, Letley L, Martin J, Mt-Isa S, Parsons S, Vickers M, Whyte K. Advice to use topical or oral ibuprofen for chronic knee pain in older people: randomised controlled trial and patient preference study. BMJ. 2008; 336(7636): 138-42.

[40] Tugwell PS, Wells GA, Shainhouse JZ. Equivalence study of a topical diclofenac solution (pennsaid) compared with oral diclofenac in symptomatic treatment of osteoarthritis of the knee: A randomized controlled trial. J Rheumatol. 2004; 31(10): 2002-12.

[41] Simon LS, Grierson LM, Naseer Z, Bookman AA, Zev Shainhouse J. Efficacy and safety of topical diclofenac containing dimethyl sulfoxide (DMSO) compared with those of topical placebo. DMSO vehicle and oral diclofenac for knee osteoarthritis. Pain. 2009; 143(3): 238-45.

[42] Zhang W, Doherty M, Leeb BF et al. EULAR evidence based recommendations for the management of hand osteoarthritis: report of a Task Force of the EULAR Standing Committee for International Clinical Studies Including Therapeutics (ESCISIT). Ann Rheum Dis. 2007; 66(3): 377-88. 
[43] Baraf HS, Gloth FM, Barthel HR, Gold MS, Altman RD. Safety and efficacy of topical diclofenac sodium gel for knee osteoarthritis in elderly and younger patients: pooled data from three randomized, double-blind, parallel-group, placebocontrolled, multicentre trials. Drugs Aging. 2011; 28 (1): 27-40.

[44] Makris UE, Kohler MJ, Fraenkel L. Adverse effects of topical non-steroidal antiinflammatory drugs in older adults with osteoarthritis: a systematic literature review.J Rheumatol. 2010; 3(6): 1236-43.

[45] Martin D, Valdez J, Boren J, Mayersohn M. Dermal absorption of camphor, menthol, and methyl salicylate in humans. J of Clin Pharmacol. 2004; 44(10): 1151-7.

[46] Shackel NA, Day RO, Kellett B, Brooks PM. Copper-salicylate gel for pain relief in osteoarthritis: a randomised controlled trial. Med J of Aust. 1997; 167(3): 134-6.

[47] Morton I, Hall J. The Royal Society of Medicine: Medicines. 6th Edition. London: Bloomsbury, 2002.

[48] Nilius B, Owsianik G, Voets T, Peters JA. Transient receptor potential cation channels in disease. Physiol Rev. 2007; 87(1): 165-217.

[49] Stanos SP. Topical agents for the management of musculoskeletal pain. J of Pain and Symptom Manage. 2007; 33(3): 342-55.

[50] Prescription Cost Analysis, England. 2006ISBN: 1-84636-035-6 2006.

[51] Matthews P, Derry S, Moore RA, McQuay HJ. Topical rubefacients for acute and chronic pain in adults. Cochrane Database Syst Rev. 2009 Jul 8; (3): CD007403.

[52] Mason L, Moore RA, Edwards JE, McQuay HJ, Derry S, Wiffen PJ. Systematic review of efficacy of topical rubefacients containing salicylates for the treatment of acute and chronic pain. BMJ. 2004 Apr 24; 328(7446): 995.

[53] Baron R. Capsaicin and nociception: from basic mechanisms to novel drugs. Lancet. 2000; 356(9232): 785-7.

[54] Nolano M, Simone DA, Wendelschafer-Crabb G, Johnson T, Hazen E, Kennedy WR. Topical capsaicin in humans: parallel loss of epidermal nerve fibres and pain sensation. Pain 1999; 81(1-2): 135-45.

[55] Mason L, Moore RA, Derry S, Edwards JE, McQuay HJ. Systematic review of topical capsaicin for the treatment of chronic pain. BMJ. 2004; 328(7446): 991-94.

[56] Cameron MH. Physical agents in rehabilitation. From research to practice. Philadelphia: WB Saunders Company, 1999.

[57] Arthritis Foundation. Conditions and treatments. Disease Centre. http://www.arthriitis.org/conditions/DiseaseCenter? Oa.asp., 2003

[58] Brosseau L, Yonge KA, Robinson V, Marchand S, Judd M, Wells G, Tugwell P. Thermotherapy for treatment of osteoarthritis. Cochrane Database Syst Rev 2003; (4): CD004522.

[59] Yurtkuran M, Kocagil T. TENS, Electroacupuncture and Ice Massage: Comparison of Treatment for Osteoarthritis of the Knee. Am J of Acupunct. 1999; 27(3-4): 133-40.

[60] Clarke GR, Willis LA, Stenner L, Nichols PJR. Evaluation of Physiotherapy in the Treatment of Osteoarthrosis of the Knee. Rheumatol Rehabil. 1974; 13(4): 190-7.

[61] Hecht PJ, Backmann S, Booth RE, Rothman RH. Effects of Thermal Therapy on Rehabilitation after Total Knee Arthroplasty : A Prospective Randomized Study. Clinical Orthopadics and Related Research 1983; 178: 198-201. 
[62] Yildirim N, Filiz Ulusoy M, Bodur H. The effect of heat application on pain, stiffness, physical function and quality of life in patients with knee osteoarthritis. J Clin Nurs. 2010; 19(7-8): 1113-20.

[63] Valdes K, Marik T. A systematic review of conservative interventions for osteoarthritis of the hand. J Hand Ther. 2010; 23(4): 334-50.

[64] Boustedt C, Nordenskiold U, Nilsson AL. Effects of a hand joint protection programme with an addition of splinting and exercise. Clin Rheumatol. 2009; 28: 793-9.

[65] Pyne D, Ioannou Y, Mootoo R, Bhanji A. Intra-articular steroids in knee osteoarthritis: a comparative study of triamcinolone hexacetonide and methylprednisolone acetate. Clin Rheumatol. 2004; 23(2): 116-20.

[66] Schumacher HR. Aspiration and injection therapies for joints. Arthritis Rheum. 2003; 49(3): 413-20.

[67] Friedman DM \& Moore ME. The efficacy of intra-articular steroids in osteoarthritis: a double blind study. J Rheumatol. 1980; 7(6): 850-6.

[68] Dieppe PA, Sathapatayavongs B, Jones HE, Bacon PA, Ring EF. Intra-articular steroids in osteoarthritis. Rheumatol Rehab. 1980; 19(4): 212-17.

[69] Gaffney K, Ledingham J, Perry JD. Intra-articular triamcinolone hexacetonide in knee osteoarthritis: factors influencing the clinical response. Ann Rheum Dis. 1995; 54(5): 379-81.

[70] Jones A \& Doherty M. Intra-articular corticosteroids are effective in osteoarthritis but there are no clinical predictors of response. Ann Rheum Dis. 1996; 55(11): 829-32.

[71] Bellamy N, Campbell J, Robinson V, Gee T, Bourne R, Wells G. Intra-articular corticosteroids for osteoarthritis of the knee. Cochrane Database Syst Rev. 2006 Apr 19; (2): CD005328.

[72] Flanagan J, Casale FF, Thomas TL, Desai KB. Intra-articular injection for pain relief in patients awaiting hip replacement. Ann R Coll Surg Engl. 1988; 70(3): 156-7.

[73] Qvistgaard E, Christensen R, Torp-Pedersen S, Bliddal H. Intra-articular treatment of hip osteoarthritis: a randomized trial of hyaluronic acid, corticosteroid, and isotonic saline. Osteoarthritis Cartilage. 2006; 14(2): 163-70.

[74] Meenagh GK, Patton J, Kynes C, Wright GD. A randomised controlled trial of intraarticular corticosteroid injection of the carpometacarpal joint of the thumb in osteoarthritis. Ann Rheum Dis. 2004; 63(10): 1260-3.

[75] Day CS, Gelberman R, Patel AA, Vogt MT, Ditsios K, Boyer MI. Basal joint osteoarthritis of the thumb: a prospective trial of steroid injection and splinting. J Hand Surg. 2004; 29(2): 247-51.

[76] Ayral X. Injections in the treatment of osteoarthritis. Best Pract Res Clin Rheumatol. $2001 ; 15(4), 609-26$.

[77] Chao J, Wu C, Sun B, Hose MK, Quan A, Hughes TH, Boyle D, Kalunian KC. Inflammatory characteristics on ultrasound predict poorer longterm response to intraarticular corticosteroid injections in knee osteoarthritis. J Rheumatol. 2010; 37(3): 650-5.

[78] Schumacher HR, Chen LX. Injectable corticosteroids in treatment of arthritis of the knee. Am J Med 2005; 118(11): 1208-14.

[79] Creamer P. Intra-articular corticosteroid treatment in osteoarthritis. Curr Opin Rheumatol. 1999; 11(5): 417-21. 
[80] Kumar N, Newman RJ. Complications of intra- and peri-articular steroid injections. Br J Gen Pract. 1999; 49(443): 465-6.

[81] Pattrick M, Doherty M. Facial flushing after intra-articular injection of bupivacaine and methylprednisolone. BMJ. 1987; 295(6610): 1380.

[82] Slotkoff A, Clauw D, Nashel D. Effect of soft tissue corticosteroid injection on glucose control in diabetics. Arthritis Rheum. 1994; 37(suppl 9): S347.

[83] Papacrhistou G, Anagnostou S, Katsorhis T. The effect of intraarticular hydrocortisone injection on the articular cartilage of rabbits. Acta Orthop Scand. Suppl. 1997; 275: 132-4.

[84] Raynauld JP, Buckland-Wright C, et al. Safety and efficacy of long-term intraarticular steroid injections in osteoarthritis of the knee: a randomized, double-blind, placebocontrolled trial. Arthritis Rheum. 2003; 48(2): 370-7.

[85] Fife R. Osteoarthritis: A. Epidemiology, pathology and pathogenesis. In: Klippel JH, editor. Primer on the rheumatic diseases. 11th edition. Atlanta: The Arthritis Foundation; 1997. p. 216-7.

[86] Bellamy N, Campbell J, Robinson V, Gee T, Bourne R, Wells G. Viscosupplementation for the treatment of osteoarthritis of the knee. Cochrane Database Syst Rev. 2006 Apr 19; (2): CD005321.

[87] Wobig M, Bach G, Beks P, et al. The role of elastoviscosity in the efficacy of viscosupplementaion for osteoarthritis of the knee: A comparison of hylan G-F 20 and a lower molecular weight hyaluronan. Clin Ther. 1999; 21(9): 1549-62.

[88] Qvistgaard E, Christensen R, Torp-Pedersen S, Bliddal H. Intra-articular treatment of hip osteoarthritis: a randomized trial of hyaluronic acid, corticosteroid, and isotonic saline. Osteoarthritis Cartilage. 2006; 14(2): 163-70.

[89] Fuchs S, Mönikes R, Wohlmeiner A, Heyse T. Intra-articular hyaluronic acid compared with corticoid injections for the treatment of rhizarthrosis. Osteoarthritis Cartilage. 2006; 14(1): 82-8.

[90] Ernst E. Acupuncture as a symptomatic treatment of osteoarthritis. A systematic review. Scand J Rheumatol. 1997; 26(6): 444-7.

[91] C Witt, B Brinkhaus, S Jena, et al. Acupuncture in patients with osteoarthritis of the knee: a randomised trial. Lancet. 2005; 366(9480): 136-43.

[92] Molsberger A, Böwing G, Jensen KU, Lorek M.[Accupuncture treatment for the relief of gonarthrosis pain-a controlled clinical trial]. Der Schmerz 1994; 8(1): 37-42. German.

[93] Petrou P, Winkler V, Genti G, Balint G. Double blind trial to evaluate the effect of acupuncture treatment on knee osteoarthritis. Scand J Acupunct. 1988; 3: 112-15.

[94] Berman BM, Singh BB, Lao L, et al. A randomized trial of acupuncture as an adjunctive therapy in osteoarthritis of the knee. Rheumatology (Oxford). 1999; 38(4): 346-54.

[95] Ezzo J, Hadhazy V, Birch S, Kaplan G, Hochberg M, Berman B. Acupuncture for osteoarthritis of the knee: a systematic review. Arthritis Rheum. 2001; 44(4): 819-25.

[96] Christensen BV, Luhl IU, Vilbek H, Bulow HH, Dreijer NC, Rasmussen HF. Acupuncture treatment of severe knee osteoarthrosis: a long-term study. Acta Anaesthesiol Scand. 1992; 36(6): 519-25.

[97] Foster NE, Thomas E, Barlas P, Hill JC, Young J, Mason E, et al. Acupuncture as an adjunct to exercise based physiotherapy for osteoarthritis of the knee: randomised controlled trial. BMJ 2007; 335(7617): 436. 
[98] Yamashita H, Tsukayama H, Hori N, Kimura T, Tanno Y. Incidence of adverse reactions associated with acupuncture. J Altern Complement Med. 2000; 6(4): 345-50.

[99] Melchart D, Weidenhammer W, Streng A Reitmayr S, Hoppe A, Ernst E, Linde K. Prospective investigation of adverse effects of acupuncture in 97733 patients. Arch Intern Med. 2004; 164(1): 104-5.

[100] Berman BM, Lao L, Langenberg P, Lee WL, Gilpin AM, Hochberg MC. Effectiveness of Acupuncture as Adjunctive Therapy in Osteoarthritis of the Knee. Ann Intern Med. 2004; 141(12): 901-10.

[101] Ernst E, White A. Acupuncture: safety first. BMJ. 1997; 314(7091): 1362.

[102] Steindler A and Luck JV. Differential diagnoses of pain in the low back. J. Amer. Med. Assoc. 1938; 110:106-113.

[103] Travell JG, Simons DG (eds.) Myofascial Pain and Dysfunction: the Trigger Point Manual. Williams \& Wilkins, Baltimore, MD, USA, 1983: 2-18.

[104] Cailliet R. Chronic pain concept. In: Soft Tissue Pain and Disability. FA Davis, Philadelphia, PA, USA, 1977: 25-40.

[105] Mann F: Acupuncture: the Ancient Chinese Art of Healing. Heinemann, London, 1971: 28-30.

[106] Fox WW and Freed DLJ. Understanding arthritis. Macmillan, London, 1990.

[107] Scott NA, Guo B, Barton PM, Gerwin RD. Trigger point injections for chronic nonmalignant musculoskeletal pain: a systematic review. Pain Med. 2009; 10(1): 54-69.

[108] Kim PS. Role of injection therapy: review of indications for trigger point injections, regional blocks, facet joint injections, and intra-articular injections. Curr Opin Rheumatol. 2002; 14(1): 52-7.

[109] Sidel N and Abrams MI. Treatment of chronic arthritis; results of vaccine therapy with saline injections used as controls. J. Am. Med. Assoc. 1940; 11:1740-1742.

[110] Traut EF, Passarelli EW. Study in the controlled therapy of degenerative arthritis. Arch. Intern. Med. 1956; 98(2): 181-186.

[111] Frost FA, Jessen B, Siggaard-Andersen J. A controlled, double-blind comparison of mepivacaine versus saline injection for myofascial pain. Lancet. 1980; 1(8167): 499500.

[112] Frost FA. Diclofenac versus lidocaine as injection therapy in myofascial pain. Scand J Rheumatol. 1986; 15: 153-156.

[113] Byrn C, Olsson I, Falkheden L et al. Subcutaneous sterile water injections for chronic neck and shoulder pain following whiplash injuries. Lancet. 1993; 341(8843): 44952.

[114] Fricton JR. Management of masticatory myofascial pain. Semin Orthod 1995; 1: 22943.

[115] Fischer AA. Algometry in the daily practice of pain management. J Back Musculoskelet Rehabil 1997; 8: 151-63.

[116] Yentür EA, Okcu G, Yegul I. The role of trigger point therapy in knee osteoarthritis. Pain Clinic 2003; 15: 385-90.

[117] Fox WW: Arthritis therapy. In Machtey I (ed.) Progress in Rheumatology Golda Medical Centre, Peta-Tigva, 1987; 3: 242-5.

[118] Mackworth-Young CG. Treatment of osteoarthritis by cutaneous injection of salicylate or saline: a pilot study. J Orthop Med. 2000; 22: 75-80. 
[119] Smith AS, Doré CJ, Dennis L, Julius A, Mackworth-Young CG. A randomised controlled trial of subcutaneous sodium salicylate therapy for osteoarthritis of the thumb. Postgrad Med J. 2010; 86(1016): 341-5.

[120] Kidd BL, Urban LA. Mechanisms of inflammatory pain. Br J of Anaesth. 2001; 87(1): 311.

[121] Schaible HG, Ebersberger A, Von Banchet GS. Mechanisms of pain in arthritis. Ann N Y Acad Sci. 2002; 966: 343-54.

[122] Holzer P. Local effector functions of capsaicin-sensitive sensory nerve endings: involvement of tachykinins, calcitonin gene-related peptide and other neuropeptides. Neuroscience 1988; 24(3): 739-68.

[123] McCarthy GM, McCarty DJ Effect of topical capsaicin in the therapy of painful osteoarthritis of the hands. J. Rheumatol. 1992; 19: 604-607 


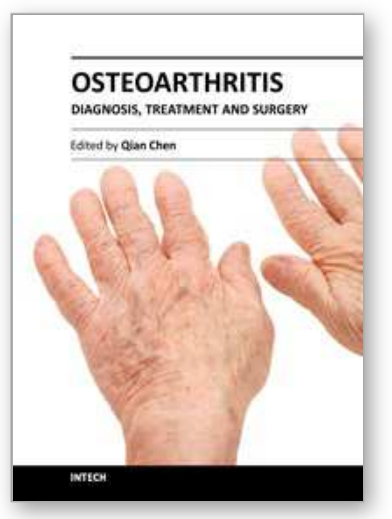

\author{
Osteoarthritis - Diagnosis, Treatment and Surgery \\ Edited by Prof. Qian Chen
}

ISBN 978-953-51-0168-0

Hard cover, 404 pages

Publisher InTech

Published online 02, March, 2012

Published in print edition March, 2012

Osteoarthritis is one of the most debilitating diseases affecting millions of people worldwide. However, there is no FDA approved disease modifying drug specifically for OA. Surgery remains an effective last resort to restore the function of the joints. As the aging populations increase worldwide, the number of OA patients increases dramatically in recent years and is expected to increase in many years to come. This is a book that summarizes recent advance in OA diagnosis, treatment, and surgery. It includes wide ranging topics from the cutting edge gene therapy to alternative medicine. Such multifaceted approaches are necessary to develop novel and effective therapy to cure OA in the future. In this book, different surgical methods are described to restore the function of the joints. In addition, various treatment options are presented, mainly to reduce the pain and enhance the life quality of the OA patients.

\title{
How to reference
}

In order to correctly reference this scholarly work, feel free to copy and paste the following:

Leena Patel and Charles Mackworth-Young (2012). Topical and Regional Treatment for Osteoarthritis, Osteoarthritis - Diagnosis, Treatment and Surgery, Prof. Qian Chen (Ed.), ISBN: 978-953-51-0168-0, InTech, Available from: http://www.intechopen.com/books/osteoarthritis-diagnosis-treatment-and-surgery/topical-andregional-treatment-for-osteoarthritis

\section{INTECH}

open science | open minds

\author{
InTech Europe \\ University Campus STeP Ri \\ Slavka Krautzeka 83/A \\ 51000 Rijeka, Croatia \\ Phone: +385 (51) 770447 \\ Fax: +385 (51) 686166 \\ www.intechopen.com
}

\author{
InTech China \\ Unit 405, Office Block, Hotel Equatorial Shanghai \\ No.65, Yan An Road (West), Shanghai, 200040, China \\ 中国上海市延安西路65号上海国际贵都大饭店办公楼405单元 \\ Phone: +86-21-62489820 \\ Fax: $+86-21-62489821$
}


(C) 2012 The Author(s). Licensee IntechOpen. This is an open access article distributed under the terms of the Creative Commons Attribution 3.0 License, which permits unrestricted use, distribution, and reproduction in any medium, provided the original work is properly cited. 